\title{
Stakeholder Collaboration Mechanism in Elderly Community Retrofit Projects: Case Study in China
}

\author{
Li Guo $^{1,2}$, Shuya Hao ${ }^{2}$, Udara Ranasinghe ${ }^{3}$, Maggie Liyaning Tang ${ }^{3}\left(\mathbb{C}\right.$ and Mary Hardie ${ }^{4, *}$ \\ 1 Department of Civil Engineering, National Chiao Tung University, Hsinchu 300, Taiwan; guoli@bucea.edu.cn \\ 2 School of Economics and Management Engineering, Beijing University of Civil Engineering and Architecture, \\ Beijing 100037, China; 18811323219@163.com \\ 3 School of Architecture and Built Environment, The University of Newcastle, Newcastle, NSW 2308, Australia; \\ uranasingheranawalage1@newcastle.edu.au (U.R.); Maggie.Tang@newcastle.edu.au (M.L.T.) \\ 4 School of Engineering, Design and Built Environment, Western Sydney University, \\ Penrith, NSW 2750, Australia \\ * Correspondence: M.Hardie@westernsydney.edu.au
}

Citation: Guo, L.; Hao, S.;

Ranasinghe, U.; Tang, M.L.; Hardie,

M. Stakeholder Collaboration Mechanism in Elderly Community Retrofit Projects: Case Study in China. Sustainability 2021, 13, 10759. https:/ / doi.org/10.3390/su131910759

Academic Editor: Avi Friedman

Received: 21 August 2021

Accepted: 25 September 2021

Published: 28 September 2021

Publisher's Note: MDPI stays neutral with regard to jurisdictional claims in published maps and institutional affiliations.

Copyright: (c) 2021 by the authors. Licensee MDPI, Basel, Switzerland. This article is an open access article distributed under the terms and conditions of the Creative Commons Attribution (CC BY) license (https:/ / creativecommons.org/licenses/by/ $4.0 /)$.

\begin{abstract}
The aged population all over the world is predicted to increase over the next couple of years. Especially in China, the ageing population is expanding significantly every year. A 'Home-care model' is becoming the first choice for many elders in China due to the traditional style of community and economic considerations. However, existing communities generally lack supporting facilities for their elders. This can result in hidden safety risks in these communities. Consequently, retrofit projects among these communities of elders have attracted attention and generated studies in both academia and industry. Such elderly community retrofit projects (ECRPs) involve multiple stakeholders, and therefore, the establishment of an effective synergy mechanism for all stakeholders would provide significant value for the successful implementation of ECRPs. Until now, no such mechanism has been developed and published. This research aims to develop a stakeholder collaboration mechanism (SCM) for ECRPs in China. As the method of data collection, interviews with relevant ECRP stakeholders were conducted. Stakeholders involved with ECRPs were classified into three main categories-namely, core stakeholders (ageing families, government organisations, and ECRP companies), dormant stakeholders (other residents, other investors community committees), and marginal stakeholders (financial institutions, property service enterprises, and public welfare organisations). Finally, the SCM was developed utilising a power-interest matrix. Actions for stakeholders were recommended in order to promote ECRP in China.
\end{abstract}

Keywords: stakeholder collaboration mechanism (SCM); elderly community retrofit projects (ECRP); China

\section{Introduction}

As the ageing proportion of the population all over the world is increasing rapidly, ensuring proper ageing facilities for the elderly has become a vital need. The United Nations Population Division predicted that the elderly population would increase by more than 8 million people per year. By 2025, older adults in China will reach 298 million, and this number will increase to 498 million in 2050. 'Elderly' is defined as people over 60 years old [1]. By the end of 2017, there were about 240 million elderly people in China, $84 \%$ of whom lived in residential areas built before 2000 , where no suitable ageing facilities have been included in the residential area designs [2]. Wang [3] pointed out that the old communities in China generally face many difficulties in households. These include issues such as height differences in the floor levels of the houses, lack of thermal insulation for doors, windows and walls, insufficient protection against falls, inadequate lighting equipment, and no emergency call system yet established in households. A survey on the living conditions of the elderly in urban and rural areas in China in 2015 shows that $58.7 \%$ 
of them believed that there is a problem of discomfort in their houses, and $16.1 \%$ have fallen due to poor conditions at home. Death caused by falls, the inability to call the police in an emergency at home, and the inconvenience of toilet and bathing facilities are a few of the problems faced by the elderly in both urban and rural areas [4]. This highlights the vital need for elderly community retrofit projects (ECRPs) to improve the living conditions of the elderly community.

In recent times, a lot of attention has been focused on enhancing the quality of life of older people [5]. ECRP is one successful approach that enhances the quality of life of the elderly by creating age-friendly homes. Elderly people would benefit from these ECRPs, as they planned to address the many difficulties faced by an older person in a traditional household, such as falling, fatigue, and diminished sitting and standing tolerances. Therefore, ECRPs provide alterations, modifications, or additions to the elder's homes in order to maximise their ability to perform their daily tasks without any help [6]. This could include change of finishes, layout, and structure of the home, furniture and lighting, installation of step-free access and rails, and control over equipment and services to improve the home environment [6].

Governments at all levels actively promote suitable ECRPs in China. The 'Opinions on the Development and Implementation of Elderly Care Services Projects' Guobanfa-2017, No. 52, pointed out that the effective cooperation of stakeholders is the key to the success of the ECRP. Further, the National Working Committee on Ageing has implemented the '13th Five-Year Plan for the Development of National Ageing Careers and the Construction of the Elderly Care System', which pointed out the necessity of promoting renovations in old residential areas, the renovation of shantytowns, and dilapidated houses in rural areas. They designed a series of renovation rules to improve existing facilities. Local governments in China have also actively responded to the central government's strategy. For example, Beijing has introduced policies related to 'Age-care Facilities and Barrier-free Transformation' and Yunnan, Shandong, Henan, Zhejiang, and other provinces and cities have launched policies that support ECRP.

From the literature on ECRP, it is found that mutual cooperation among stakeholders is an important factor for the success of ECRP. Therefore, this article develops a stakeholder coordination mechanism (SCM) that explains the demands and relationships of various stakeholders based on the power-interest matrix and analyses their collaborative status scientifically. Therefore, this study established two research objectives as (1) identification and division of stakeholders in ECRP and (2) development of stakeholder collaboration mechanism for ECRP in China.

\section{Literature Review}

\subsection{ECRP Practices}

The ECRP has great market potential in China [7]. According to a survey conducted by the Ministry of Housing and Urban-Rural Development, there are 40 billion $\mathrm{m}^{2}$ of old domestic buildings in China, and the direct market share of home-age retrofit is 3 trillion yuan. Zou and Li [8] pointed out that if two elderly people are living in a house, and the price of renovating a home is calculated on the basis of an average of 30,000 yuan, then the market share of ECRP will reach 328.05 billion yuan by 2022 [8].

In reality, there are a number of potential problems in delivering ECRP. There are several reasons for this, such as lack of unified standards and pricing mechanisms, and there is no established pricing basis for ECRP in the industry $[2,9,10]$. There is a huge gap between the supply and demand for funds and a lack of government capital investment $[9,11]$. The unwillingness of many residents to retrofit homes, and lack of understanding of the concept of ECRP is also an issue $[3,12,13]$. Lastly, insufficient top-level design expertise and a lack of policy guarantees and promotion mechanisms for ECRP currently exist [14-16]. In general, the difficulty of retrofit is that each stakeholder focuses on its own defects and lacks a unified coordination mechanism to cooperate with each other [11]. 
Compared to China, some developed countries have relatively comprehensive adaptation systems, with clear management organisations and evaluation standards. For example, assessment systems such as CASPAR have been developed for comprehensive assessment and renovation of the home environment for the elderly, as well as, SAFER for rehabilitation and environmental safety assessment, and Housing Enabler [17]. The concept of 'senior housing' was introduced in northern Europe in the early 1970s. In 1982, the Vienna International Plan of Action on Aging was created to meet the special needs of the elderly. Among the seven special needs of the elderly listed, 'housing and environment' rank in the second position, which demonstrates the importance of the residential environment. Singapore's 'General Design Guidelines' related different elderly care needs to different populations and stages and designed multiple channels for financing. This resulted in the popularity of ECRP in Singapore. Sweden's ECRP has formed a relatively complete service system from policy support to the service application mechanism and various supporting service facilities for ECRP implementation, supervision, and evaluation $[18,19]$. The Community Housekeeping System in France provides feasibility assessment and technical guidance for the renovation of elderly apartments. Further, 'social architecture' in the United States, which provides policies and practical guidance for ECRP, and the 'street building movement' that promotes ECRP in Japan, are interesting contributions.

Research outside of China has paid more attention to healthy and green retrofit projects and has a relatively complete assessment system for housing retrofit projects. This assessment system is very clear to stakeholders involved in retrofit projects, and their coordination mechanism is well defined. China's retrofit projects are relatively underdeveloped, compared to outside China, due to previously mentioned barriers that hinder ECRPs. As a result, many researchers have raised the importance of collaboration among various stakeholders $[4,9,11]$. Therefore, the establishment of a stakeholder coordination mechanism may effectively solve this issue. In terms of research methods, most ECRP related research uses literature analysis methods, and some researchers establish data models through quantitative and qualitative data analysis [4,19-21]. In addition, the game theory method $[22,23]$ and social network analysis (SNA) $[24,25]$ are widely used methods of analysis in stakeholder management research.

\subsection{Stakeholder Identification and Division Based on the Whole Process of ECRP}

Firstly, it is important to identify and divide the stakeholders in ECRP in order to achieve the first objective of the research. After an extensive review of textual information, the whole process of implementation of the appropriate ECRP is summarised into three major stages: before ECRP, during ECRP, and after ECRP. The stakeholders involved in each stage were identified after a comprehensive review of the literature (see Table 1). However, the retrofit process can be slightly changed from region to region due to cultural differences. Figure 1 shows the three stages of ECRP and the main stakeholder participants in each stage. Further, it illustrates stakeholder cooperation and work tasks performed by various stakeholders in different stages of ECRP.

Government organisations, elderly families, community neighbourhood committees, property service companies, and ECRP companies are the stakeholders that are mainly involved in ECRP. Government organisations include the central government, local governments, and sub-district offices. From the perspective of government planning, Liu and Chen [26] proposed that ECRP requires policy support and social support, such as welfare security policies and community participation. Dai and Wang [27] systematically sorted out the experience of community renovation activities outside of China and suggested promoting the sustainable development of ECRP for government, community management, and financial institutions. Zhang [28] divided various stakeholders into 'shared type', 'co-constructed type', and 'symbiotic type' in order to propose suggestions to promote suitable retrofit projects. The main stakeholders identified from the literature review are shown in Table 1. 


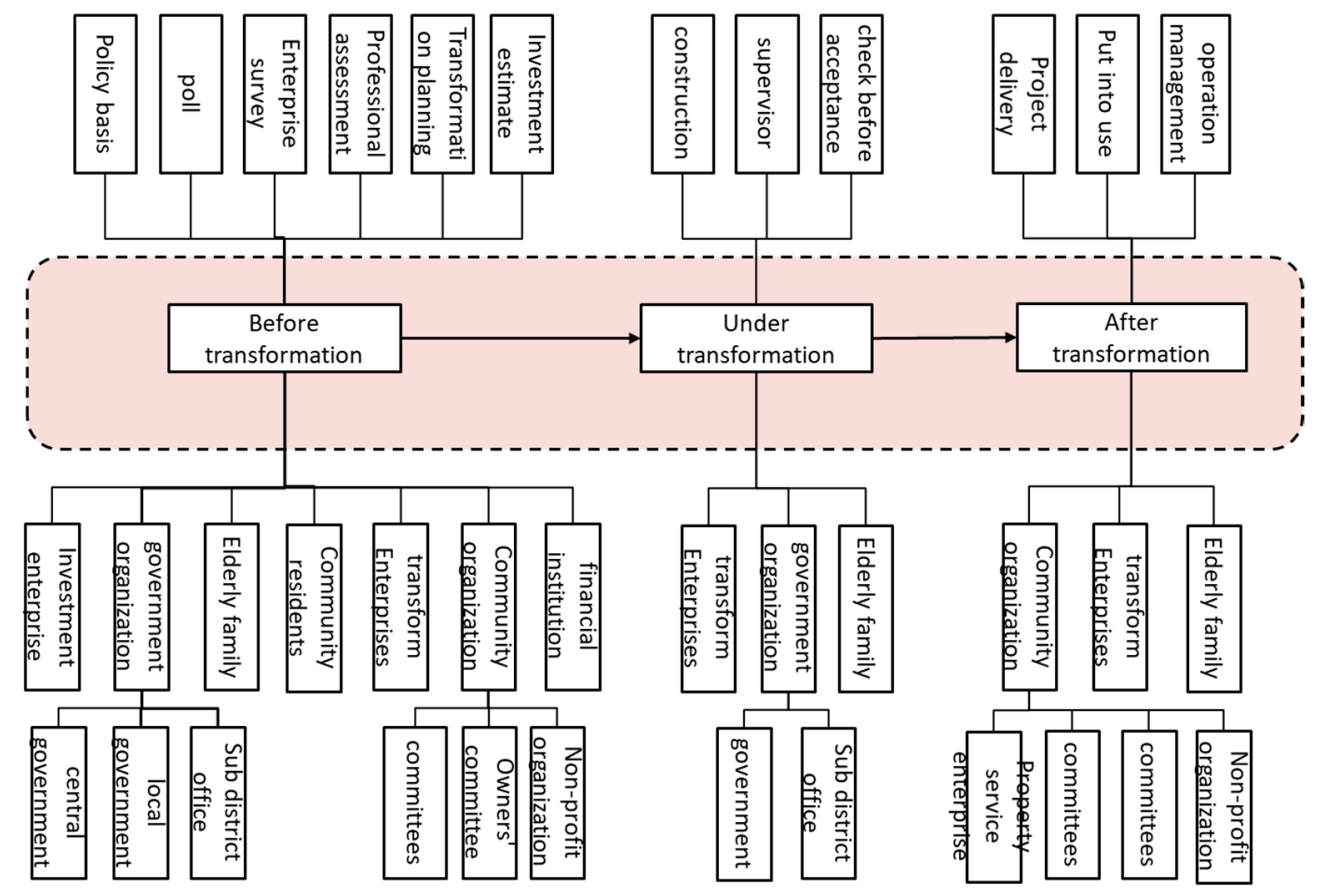

Figure 1. Stakeholder identification for ECRP.

Table 1. Main stakeholders.

\begin{tabular}{ccc}
\hline Number & $\begin{array}{c}\text { Stakeholders (Document Research } \\
\text { Results) }\end{array}$ & Sources \\
\hline S1 & Senior (elderly) family & {$[3,4,10,14,22,29]$} \\
\hline S2 & ECRP companies & {$[2,22,27,30]$} \\
\hline S3 & Government organisation & {$[2,3,14,22,27,30,31]$} \\
\hline S4 & Community committees & {$[14,22,27,32]$} \\
\hline S5 & Property Service companies & {$[22,27,33]$} \\
\hline S6 & Non-governmental organisations / public & {$[10,22,30,31]$} \\
\hline S7 & welfare organisations & {$[28,31]$} \\
\hline S8 & Financial Institutions & {$[33]$} \\
\hline S9 & Other investors of the project & {$[14,30-32]$} \\
\hline
\end{tabular}

S1-senior/elderly family. Older families are the most highlighted and important stakeholders in ECRP, and they are the consumers and the biggest beneficiaries of ECRPs.

S2-suitable ECRP companies. According to the literature, the studies based on ECRP mainly focuses on services provided by ECRP enterprises as they are the people who carried out retrofit in existing houses.

S3-government organisations. In the literature on dynamic evolutionary games and stakeholder theories [34,35], government organisations have always been at the core of high power. Compared with other stakeholders, government organisations pay more attention to social benefits rather than economic benefits [2,3,32]. In stakeholder coordination mechanisms, they mostly engage with improving policies, establishing standards, and coordinating various parties $[14,22,30]$.

S4-community neighbourhood committees. As a subordinate unit of the street office, the community neighbourhood committee interacts closely with the community residents daily and plays an important coordination role in the stakeholder coordination mechanism $[14,22,27,32]$. 
S5-property service companies. Most of the community public equipment maintainers after the ECRPs are property service companies [10]. There are many studies on capital issues and operation and maintenance carried out in aged-care facilities by property service companies $[22,30,31]$.

S6-non-governmental organisations/public welfare organisations. As a voluntary public welfare organisation, although they have low power and receive low benefits from ECRP, they have an important auxiliary role in building a collaborative mechanism for ECRP $[10,22]$. Non-profit organisations can promote the ECRP concepts and increase the acceptance rate of ECRPs by community residents [30,31].

S7-financial institutions. In the literature, financial institutions are important organisations that provide required funds to the ECRP $[28,31]$. They have relatively low power in the coordination mechanism of ECRP and have little impact on ECRP, but through a variety of financing methods, they can stimulate the vitality of the ECRP market.

S8-other investors in the project. Most of the other investors are investors of largescale ECRPs. Their funds are used for ECRPs in urban renewal and community renewal. The main motivation factor to be involved in the ECRP is to obtain more income. Therefore, they are the main source of funds in many ERPs, and their power is relatively high [33].

S9-other residents of the community. The main target of ECRP is elderly families, but it also impacts other residents in the community, especially in the communication and dissemination of information [14,32].

\subsection{Stakeholder Classification and Division Methods}

Division methods are mainly studied by researchers outside China [36], as shown in Table 2. At present, the most widely used method for the division of stakeholders is the Mitchell scoring method, which scores stakeholders using three dimensions of legality, power, and urgency [37]. One of the widely used stakeholder categorisations is the core, dormant, marginal stakeholder classification presented by Chen and Jia [38]. According to the concept and theoretical research on stakeholders, this article refers to the Chen and Jia [38] method for stakeholder division and classification.

Table 2. The stakeholder division and classification method.

\begin{tabular}{|c|c|c|c|}
\hline Author/s & Division Factors & $\begin{array}{l}\text { Stakeholder } \\
\text { Classification }\end{array}$ & Method \\
\hline [39] & Stakeholder resources & $\begin{array}{l}\text { Ownership, economic } \\
\text { dependence, social } \\
\text { benefits }\end{array}$ & $\begin{array}{l}\text { Multidimensional } \\
\text { subdivision }\end{array}$ \\
\hline$[40]$ & $\begin{array}{l}\text { How stakeholders can } \\
\text { influence the company }\end{array}$ & $\begin{array}{l}\text { Direct and indirect } \\
\text { stakeholders }\end{array}$ & $\begin{array}{l}\text { Multidimensional } \\
\text { subdivision }\end{array}$ \\
\hline$[41]$ & $\begin{array}{l}\text { Cooperative and } \\
\text { threatening }\end{array}$ & $\begin{array}{l}\text { First and second level } \\
\text { stakeholders }\end{array}$ & \\
\hline$[42]$ & $\begin{array}{l}\text { Whether there is a } \\
\text { transactional contract }\end{array}$ & $\begin{array}{c}\text { Contractual and } \\
\text { public stakeholders }\end{array}$ & $\begin{array}{l}\text { Multidimensional } \\
\text { subdivision }\end{array}$ \\
\hline$[43,44]$ & $\begin{array}{c}\text { The type of risk taking; } \\
\text { close contact with } \\
\text { the enterprise }\end{array}$ & $\begin{array}{c}\text { Voluntary and } \\
\text { involuntary, primary } \\
\text { and secondary } \\
\text { stakeholders }\end{array}$ & $\begin{array}{l}\text { Multidimensional } \\
\text { subdivision }\end{array}$ \\
\hline$[45]$ & $\begin{array}{l}\text { Legitimacy, power, } \\
\text { urgency }\end{array}$ & $\begin{array}{l}\text { Identified, expected, } \\
\text { and potential } \\
\text { stakeholders }\end{array}$ & Mitchell scoring \\
\hline$[38]$ & $\begin{array}{l}\text { Initiative, importance, } \\
\text { and urgency }\end{array}$ & $\begin{array}{l}\text { Core, dormant, } \\
\text { marginal } \\
\text { stakeholders }\end{array}$ & \\
\hline
\end{tabular}




\section{Research Methodology}

A research approach is a systematic and methodological way of addressing research questions [46]. According to Guercini [47], the quantitative research approach focuses on analysing and interpreting numerical data obtained through surveys. A qualitative research approach focuses on analysing and interpreting research participants' understanding and perceptions of the subject matter. The selection of the research approach is subject to the aim and objectives of the particular research. Researchers select a qualitative approach when there is a requirement of in-depth information related to the natural settings of the issue in achieving the research aim [47]. Hence, considering the aim and objectives, this research selected a qualitative research approach.

This study intends to develop a stakeholder collaboration mechanism (SCM) in ECRP. Therefore, a comprehensive literature review was conducted to identify the stakeholders who are engaged with ECRPs in China. Due to environmental constraints, the community under the jurisdiction of Dongfeng Street, Licheng District, Jinan City, was selected to collect data. This study selected stakeholder types of senior families, property service companies, and community committees by considering the nature of ECRP projects in China for data collection. Subsequently, face-to-face interviews were carried out with each type of stakeholder that was selected for the study. For the purpose of conducting the interview, a semi-structured questionnaire was developed. In general, the interviewee was asked about their awareness of ECRP, willingness to carry out ECRP, and the type of support they seek to start an ECRP. Due to time limitations, these stakeholders were also asked about their opinions related to other stakeholders listed in the study but not included for interviews. The questions raised during the interviews were different from one stakeholder category to another depending on their responsibilities towards ECRP. In total, 220 interviews were conducted. Semantic analyses were carried out to gather data related to ECRP companies and government organisations. Accordingly, company websites were used to collect the required information from ECRP companies. Information such as company work content, media promotion, news information, user comments, and other content were collected from the official website of ECRP companies. Policies and government documents related to ECRP were analysed to collect the required information relating to government organisations. A total of 10 government documents that were taken into consideration in this research and are shown in Table 3. The summary of the data collection method is presented in Table 4.

Table 3. List of government documents.

\begin{tabular}{c}
\hline Fumber \\
\hline 1 'Notice of the State Council on Printing and Distributing the Construction Plan \\
for the Elderly Care System for the Development of the Aged Enterprise' in the \\
'13th Five-Year Plan'-Guo Fa (2017) No. 13
\end{tabular}


Table 3. Cont.

\begin{tabular}{cc}
\hline Number & Filename \\
\hline 6 & $\begin{array}{r}\text { 'Notice of Wenzhou Ouhai District People's Government Office on Decomposing } \\
\text { and Implementing the Top Ten Practical Matters for the Ownership of Ouhai } \\
\text { District in 2017' - Wen Ou Zheng Fa (2017) No. 56 }\end{array}$ \\
\hline 7 & $\begin{array}{r}\text { 'Pilot Implementation Plan for the Ageing Improvement Project for the Families } \\
\text { of the Elderly in Need' }\end{array}$ \\
\hline 8 & 'Notice on Doing a Good Job of Renovating Old Towns in 2019' \\
\hline 10 & $\begin{array}{r}\text { 'Guiding elderly households' needs for ageing reconstruction needs assessment } \\
\text { and reform implementation management measures (trial implementation)' }\end{array}$ \\
\hline & for the Aged'-National Office for Ageing (2016) No. 73
\end{tabular}

Table 4. Data collection methods of various stakeholders.

\begin{tabular}{|c|c|c|c|}
\hline Number & Stakeholders & $\begin{array}{c}\text { Data Collection } \\
\text { Method }\end{array}$ & $\begin{array}{l}\text { Number of } \\
\text { Interviews }\end{array}$ \\
\hline S1 & Senior family & Interviews & 153 \\
\hline $\mathrm{S} 2$ & ECRP companies & $\begin{array}{c}\text { ECRP } \\
\text { company-related } \\
\text { corporate website } \\
\text { information }\end{array}$ & \\
\hline S3 & $\begin{array}{l}\text { Government } \\
\text { organisation }\end{array}$ & $\begin{array}{l}\text { Government } \\
\text { documents related to } \\
\text { policies and } \\
\text { standards }\end{array}$ & \\
\hline S4 & $\begin{array}{l}\text { Community } \\
\text { committees }\end{array}$ & Interviews & $\begin{array}{c}31 \text { members on } \\
6 \text { committees }\end{array}$ \\
\hline S5 & $\begin{array}{l}\text { Property Service } \\
\text { Enterprise }\end{array}$ & Interviews & $\begin{array}{c}36 \text { employees in } \\
8 \text { companies }\end{array}$ \\
\hline
\end{tabular}

Concern for ethical issues has become important in qualitative research when conducting interviews [48]. A few measures were taken in this research to mitigate the ethical issues associated with interviews. First, in this research, all the interviews were carried out on a voluntary basis with the consent of the interviewee. Second, participants were clearly informed about the research aim and information relevant to the data collection process. Third, the anonymity and confidentiality of participants were maintained by not disclosing their identity throughout the research.

The data collected from interviews and document searches were analysed using codebased content analysis techniques. Hence, stakeholders were classified and divided based on their behaviour and responsibility towards ECRPs. Thereafter, findings were utilised to develop the relationships between stakeholders. In order to develop a stakeholder collaboration mechanism, this study adopts the power-interest matrix. As shown in Figure 2, it is classified according to the relationship between stakeholders, their amount of power, and the degree of interest in organisational strategy. Therefore, it is called the power-interest matrix, also known as Mendelow matrix and stakeholder matrix. 


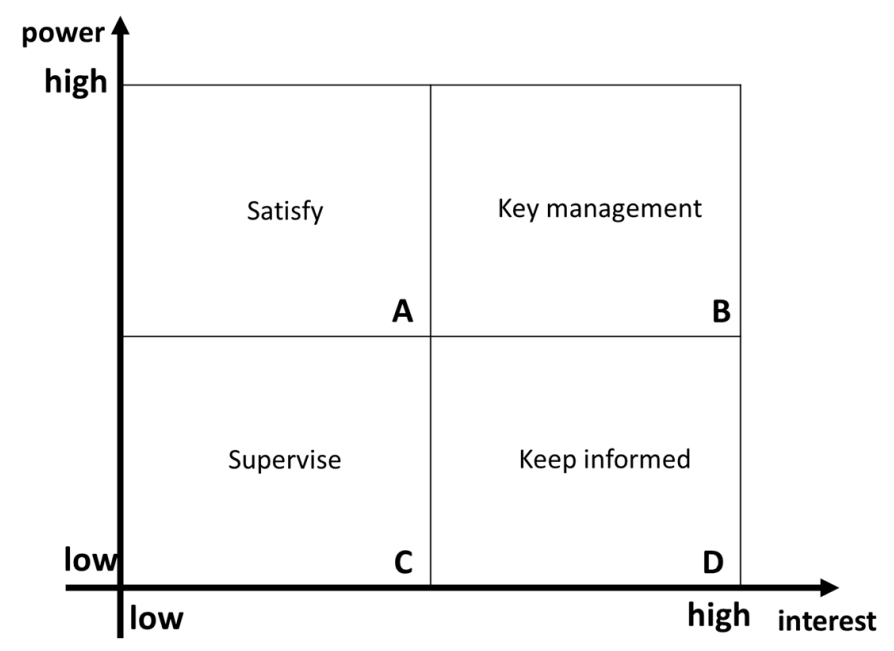

Figure 2. Power-interest matrix.

In the power-interest matrix diagram, stakeholders in area A have high power and low interest. Although their participation in activities is relatively passive, their power has a great impact on the project. Therefore, it is vital to satisfy them, pay attention to their power, and prevent them from using their power to hinder the project's development. Stakeholders in area B have a high degree of interest demand and have the greatest power to maintain themselves. Therefore, they are core stakeholders, and their approval of the project determines the success of the project. The power and interest of stakeholders in area $C$ are relatively low. Therefore, they tend to pay little attention to these groups in real life and input relatively little effort. Stakeholders in area D have lower power but higher interests. Therefore, it is necessary to maintain sufficient information flow and maintain good relationships with such stakeholders in order to prevent them from hindering the development of the project due to the reduction in interest. Qian and Ren [49] used this matrix to analyse the stakeholders in green communities and proposed corresponding management strategies. Xiong [30] used this matrix for empirically analysing community stakeholders. Geng and Chen [50] made a power-interest matrix for rural environmental problems. In summary, when considering the face of community stakeholder research, researchers often use the power-interest matrix and combine the matrix to make strategic choices. This study also uses the matrix method to develop and analyse the coordination mechanism for stakeholders in the ECRP.

\section{Findings and Discussion}

Since the ultimate beneficiaries of ECRPs are the elderly, the main interviews were carried out with elderly aged 60-90. According to the interviewees' profile of the elderly, $58(38 \%)$ of them are aged $60-79,69(45 \%)$ of them are in the age range $70-80,26(17 \%)$ of them are over 80 years old. Most of them (57\%) live with their children, 36\% live with their spouses, and only 7\% live alone. Regarding the ECRP, a general lack of knowledge about its meaning and content was observed among them. Even after the investigators made them aware of ECRP, most elderly people were reluctant to undergo ECRP in their households, mainly because they believed that ECRP is expensive and did not want to change their living environment due to low awareness of life safety, and inadequate government policy.

However, $78 \%$ of them have experienced safety problems such as bumps and falls due to poor house conditions. After making them aware of the importance of safety, the investigators asked what method of support that they are willing to accept if they think of retrofitting their houses. The methods suggested by the investigator are that of children's active support for the ECRP, the government subsidies for ECRP, the community provides sufficient information and safety supervision, and neighbours' recommendations for the ECRP. The results show that they are more willing to accept their children's support and government subsidies, which shows that the government plays an important role in 
ECRPs. In addition, neighbours also can influence the elderly to increase their acceptance of ECRPs. However, results show that the elderly community generally does not have a strong connection with community organisations.

After interviewing managers of property service companies, it was found that property service companies are closely engaged with neighbourhood committees. It was also found that the willingness of property service companies to retrofit ageing buildings is not high. However, they are not opposed to carrying out retrofit projects. Their decision to carry out retrofit depends on the support of the neighbourhood committee. At the same time, they are willing to maintain the facility after renovation. From this, it is clear that the primary factor of property service companies to participate in the retrofit project is the support they receive from community neighbourhood committees. After interviews and investigations, it was found that the willingness of the community neighbourhood committee to carry out retrofit is relatively high, especially in terms of funds and policies. However, they only know the general concept and lack the professional knowledge that greatly affects its participation in ECRP. According to the barriers for the ECRP identified during the interviews, firstly, the lack of financial support seriously affects all aspects of community construction; secondly, policy support is needed, and policy guarantee is a powerful driving force for its work; thirdly, there is a lack of understanding of ECRPs.

The current ECRP market in China is still immature. There are general rules in the ECRP market. Most of them are enforced by the government, and policy support is used to promote the development of the ECRP industry. Taking Chaoyang District in Beijing as an example, 140 elderly households were provided with free ageing renovation services in 2017. According to government documents, it can be found that the current policies of China's ECRP and the proposed retrofits for the community are mainly in the areas of barrier-free facilities, firefighting equipment, and the installation of elevators. It is clear that the government is eager to promote the process of ECRP, strengthen management, promote the development of standardisation of ECRP, strengthen the subsidy support for related enterprises and vulnerable elderly, and provide publicity for ECRP.

\subsection{Stakeholder Classification and Division Based on the Whole ECRP Process}

Based on the literature review and related survey results, this article refers to the Chen and Jia [38] stakeholder classification method. Accordingly, the relevant stakeholders in ECRP are divided into three aspects as initiative, importance, and urgency. Initiative refers to whether a certain interest group suitable for ECRP will actively promote its transformation. Importance refers to the importance of that stakeholder group in the ECRP. Urgency refers to whether the ECRP strategy change can immediately cause the group's attention. Then, stakeholders under three aspects are named as 'high, medium, and low' [37], as shown in Table 5.

Table 5. Identification and analysis of stakeholders.

\begin{tabular}{ccccc}
\hline Number & Stakeholders & Initiative & Importance & Urgency \\
\hline S1 & Senior (elderly) family & medium & high & high \\
\hline S2 & ECRP companies & high & high & high \\
\hline S3 & Government organisation & high & high & high \\
\hline S4 & Community committees & medium & high & low \\
\hline S5 & Property Service Enterprise & low & low & medium \\
\hline S6 & $\begin{array}{c}\text { Non-governmental organisations } \\
\text { public welfare organisations }\end{array}$ & medium & low & low \\
\hline S7 & Financial Institutions & low & in & low \\
\hline S8 & Other investors of the project & medium & low & medium \\
\hline S9 & Other residents of the community & low & medium & medium \\
\hline
\end{tabular}


Analysis of various stakeholders according to their initiative, importance, and urgency, has drawn on the division method, as suggested by Chen and Jia [38]. Further, stakeholders are also classified as core stakeholders, dormant stakeholders, and marginal stakeholders. These results are similar to the findings of the study of Jia and Chen [51]. Figure 3 represents the division of stakeholders into three aspects of initiative, importance, and urgency. Accordingly,

- Core stakeholders (ageing families, government organisations, and ECRP companies) represent all three attributes (initiative, importance, and urgency) and represent the area intersected by all three circles in Figure 3.

- Dormant stakeholders (other residents, other investors, and community committees) mean that they only represent two attributes. For example, in Figure 3, other residents represent the area only intersects by circles urgency and importance, other investors represent the area only intersects by circles urgency and initiative and community committees represent the area only intersects by circle imitative and importance.

- Marginal stakeholders (financial institutions, property service enterprises, public welfare organisations) mean that they only represent one attribute. For example, in Figure 3, financial institutions only represent circle importance, property service enterprises only represent circle urgency and public welfare organisations only represent circle initiatives.

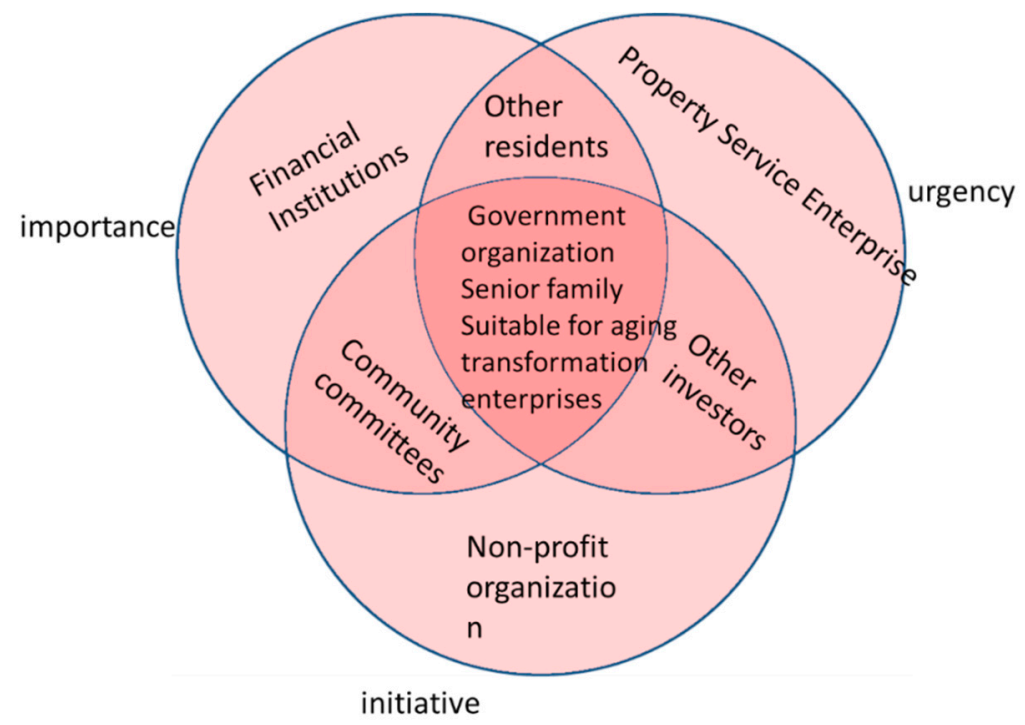

Figure 3. Stakeholder division.

\subsection{Development of Stakeholder Collaboration Mechanism Model}

On the basis of identifying and analysing ECRP stakeholder relationships, the powerinterest matrix is shown in Figure 4. The depth of colour indicates the importance of stakeholders, that is, the darkest colour is the core stakeholders, followed by dormant stakeholders, then marginal stakeholders. According to the level of power and the size of interests, it is divided into four areas of A, B, C, and D. Area A includes government organisations and community neighbourhood committees. Area B includes ECRP companies and other investors. Area $C$ includes public welfare organisations and property service enterprises. Area D has elderly families, other residents of the community, and financial institutions. 


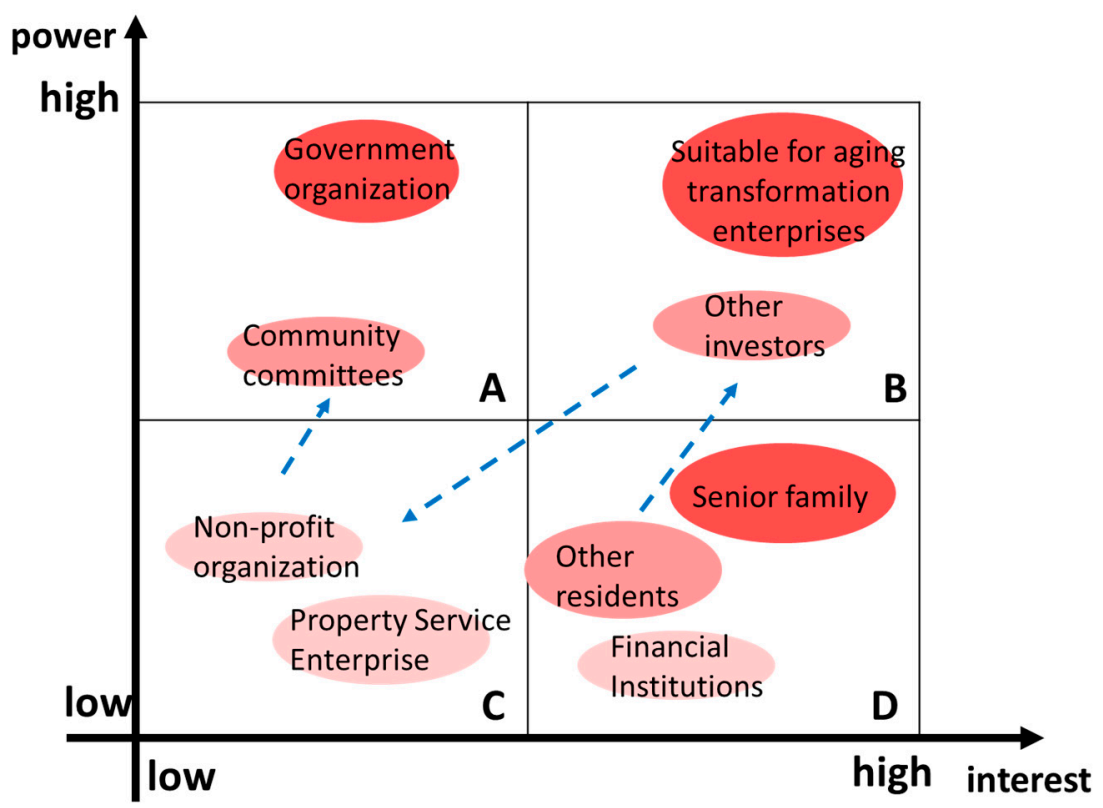

Figure 4. The collaboration mechanism model of various stakeholders.

\subsection{Discussion on Collaboration Mechanism Model}

1. Stakeholders in Area A: Area A includes government organisations and community committees. The stakeholders in this area have the highest power and certain interest. Their power is important to promote ECRPs. Particularly, community committees have the power to influence elderly people to accept ECRPs. Government organisations have significant power to establish ECRPs, as the policies issued by government organisations have an important impact on the other stakeholders in Area D. At the same time, because there are many levels of government organisations, they pay attention to internal government management, especially for street offices. Therefore, they can provide suggestions for local governments and the central government in order to revise the plans and policies to timely support ECRPs.

2. Stakeholders in Area B: Area B includes ECRP enterprises and other investors. Stakeholders in area B have high power and interest. It is very important to consider the stakeholders in area B for possible strategies for the future development of ECRPs. If the interest of the enterprise and other investors is underestimated, they will immediately relocate into zone $\mathrm{C}$. It will prevent the development of the ECRP industry to a certain extent.

3. Stakeholders in Area C: Area C mainly includes community public welfare organisations and property service companies. Although their power and interests are low, they are the organisations closest to residents and elderly families. They can have relatively more influence on the daily life of elderly families. Appropriately, increasing their power will help them to move closer to area A.

4. Stakeholders in Area D: Area D includes elderly families, other residents, and financial institutions. The stakeholders in Area D are mainly consumers who receive benefits from an ECRP. Whether or not the ECRP can be successfully implemented is closely related to their interests. Stakeholders in Area D do not have much power, but they can meet their needs in a timely manner through effective information communication, thereby promoting the concept of ECRPs. Promoting the stakeholders in area D to move closer to area B by increasing the power will increase their willingness to accept ECRPs and facilitate the cooperation between various stakeholders in the ECRP.

\subsection{Suggestions for Core Stakeholders}

- The incentive effect of government organisation: 
According to the result, it is clear that the government occupies the core position in the ECRP. In terms of financial support, government organisations should provide funds and inclusive subsidies to promote ECRPs [52]. Further, there is a vital need to establish a housing information management system for the elderly groups and implement policies according to the actual characteristics of the elderly groups. In terms of incentives, ECRP companies should be encouraged to actively participate in relevant policy development activities.

- ECRP companies should actively establish an image of integrity:

The corporate integrity of ECRP companies is an important condition for elderly families to accept an ECRP. Therefore, the integrity of the ECRP companies is an important factor in the ECRP stakeholder coordination mechanism. While enjoying preferential policies and government support such as funds, taxes, and subsidies, ECRP companies need to develop their corporate image of integrity to operate in good faith in order to fulfil their social responsibilities.

- Active participation of elderly families:

As the ultimate beneficiaries and users of ECRPs, elderly families play the most important roles in ECRPs [53]. They should respond positively to support the promotion of ECRPs [54]. At the same time, elderly families should pay attention to engage with feedback systems and information sharing to share their opinion in order to improve the effectiveness of the retrofit process.

\subsection{Suggestions for Dormant Stakeholders}

- Community neighbourhood committees should actively promote ECRP related work under the guidance of the government:

Drawing on experience from outside China, community neighbourhood committees can promote the implementation of ECRPs. At the same time, it is necessary for them to fully integrate with China's national conditions and develop a trend for ECRPs by continuously updating relevant standards.

- Community residents should strengthen their communication mechanism:

In the interviews, it was found that the stakeholders at the community level should actively make suggestions to the government, actively coordinate with other stakeholders, strengthen effective communication with other stakeholders, reflect true satisfaction, and promote the long-term development of ECRPs.

- Other investors in the project should actively seek opportunities to support ECRPs:

As dormant stakeholders, the other investors are an important source to solve the problem of funding sources and promote the ECRP. The other investors of the project should actively cooperate with core stakeholders in decision making, communicate with financial institutions, participate in arranging various investment methods, and actively promote cooperation among all ECRP stakeholders.

\subsection{Suggestions for Marginal Stakeholders}

- NGOs/public welfare organisations need to improve their recognition:

Non-profit organisations are important disseminators of policy [52]. Community non-profit organisations, financial institutions, and other organisations should establish efficient communication channels to implement appropriate ECRPs. Community non-profit organisations should communicate the ECRP concept and the importance of ECRP with residents and initiate programs to support ECRP [55]. Thus, those elderly families can promptly and proactively explain their expectations of ECRP to the community through these NGOs. Thereby, all the stakeholders can be benefitted through timely information circulating throughout the ECRP process. 
- $\quad$ Financial institutions should actively stimulate the market vitality of ECRP:

It has been found that the shortage of funds for ECRP is a serious obstacle to its development. Therefore, it is necessary to build a coordination mechanism and innovate financing models to support ECRPs. Financial institutions can suggest financing models for stimulating market vitality and increasing social investment for ECRPs.

- $\quad$ Property service companies should actively explore models suitable for operations and maintenance:

After the community has undergone ECRP, marginal stakeholders, especially property service companies, should actively supervise and explore the special maintenance needs required in the future. They should arrange sources of funds to take the initiative to undertake maintenance work. They can also share the experience and opinion of elderly families after ECRP with others to promote ECRPs in China.

\section{Conclusions}

The concept of ECRP is popular and is practiced successfully in many developed economies. However, its application is still at the early stages in China. Among the different barriers that hinder the development of ECRPs in China, the lack of a stakeholder collaboration mechanism to support ECRPs is the main cause that limits the implementation of ECRPs in China. Moreover, there is a lack of identification and division of stakeholders considering the whole process of ECRP. Therefore, this study provides insights into stakeholder involvement and their collaboration in ECRPs in China.

The study identified nine key stakeholders that are important in ECRPs in China. The stakeholder classification method and the scoring method suggested by Chen and Jia [38] was used for dividing the ECRP stakeholders into three categories: core stakeholders (government organisations, age-appropriate transformation enterprises, and elderly families), dormant stakeholders (other residents of the community; community neighbourhood committees and other investors in the project), and marginal stakeholders (property service companies, community public welfare organisations, and financial institutions). Further, stakeholders were divided into three aspects: initiative, importance, and urgency, depending on their responsibilities towards ECRPs. The power-interest matrix provides a systematic approach for analysing relationships between stakeholders. Therefore, this study developed the stakeholder collaboration mechanism (SCM) based on the powerinterest matrix. The proposed SCM will promote ECRP in China by developing proper relationships and collaboration mechanisms between stakeholders. As a core stakeholder, government organisations are important for developing ECRP as their policies, standards, and funds motivate other stakeholders. The power of the elderly family depends on whether they accept the ECRP or not. However, community neighbourhood committees and other residents are able to influence elderly families to engage with ECRPs. In addition, ECRP companies have high power and high interest over ECRP projects, compared to other stakeholders. Various types of stakeholders have strong linkages in the collaboration mechanism, and changes in one party's decision will trigger multiple stakeholders. Therefore, in order to effectively promote the development of ECRP, it is necessary to build a synergistic mechanism for ECRP stakeholders, stabilise the interaction of various stakeholders, and maximise the interests of all stakeholders involved in the project.

Due to time limitations, interviews are limited to few categories of stakeholders, with no account of all the stakeholders involved in ECRPs. In future research, empirical analysis is needed, focusing on the scientific and accurate dynamic changes of stakeholders that introduce data to numerically simulate the dynamic evolution game to clarify the decisionmaking characteristics of each core stakeholder to make the findings more realistic and promote the steady development of suitable ECRPs.

Author Contributions: Conceptualisation, L.G. and S.H.; methodology, L.G.; data analysis, S.H.; writing-original draft preparation, L.G., S.H. and M.L.T.; writing-review and editing, U.R. and M.H. All authors have read and agreed to the published version of the manuscript. 
Funding: This research received no external funding.

Institutional Review Board Statement: Not applicable.

Informed Consent Statement: Not applicable.

Data Availability Statement: Not applicable.

Acknowledgments: The authors would like to express their sincere acknowledgment to reviewers and editors for their time and efforts in providing comments and suggestions.

Conflicts of Interest: The authors declare no conflict of interest.

\section{References}

1. Wu, L.; He, Y.; Jiang, B.; Sun, D.; Wang, J.; Liu, M.; Yang, S.; Wang, Y. Trends in prevalence, awareness, treatment and control of hypertension during 2001-2010 in an urban elderly population of China. PLoS ONE 2015, 10, e0132814. [CrossRef]

2. Ruan, X.D. Home care for the elderly: Suitable for aging transformation ushered in the market outlet. New Econ. Guide 2017, $12,67-71$.

3. Wang, S. A Study on the Willingness to Renovate the Housing of the Elderly in Shanghai's Old Community. J. Econ. Res. 2019, 3, 129-130.

4. Duan, L.; Gao, Y.; Liu, Y.; Tian, J. Investigation and Research on the Aging Level of the Old People's Home Environment in Town and Community. J. Nurs. Sci. 2019, 34, 87-90.

5. Bartolomeu, P.; Fonseca, J.; Santos, V.; Mota, A.; Silva, V.; Sizenando, M. Automating home appliances for elderly and impaired people: The B-live approach. In Proceedings of the 2nd International Conference on Software Development for Enhancing Accessibility and Fighting Info-Exclusion (DSAI'07), Villa Real, Portugal, 2007.

6. Li, S.; Au Yeung, K.K.Y. Home modification programme for elderly home owners in Hong Kong. World Fed. Occup. Ther. Bull. 2016, 72, 54-57. [CrossRef]

7. Yanli, Z. Elderly Residential Space Design and Analysis: A Review. In Proceedings of the International Conference on Advances in Mechanical Engineering and Industrial Informatics, Zhengzhou, China, 11-12 April 2015.

8. Zou, C.; Li, R. Investigation and Suggestions on the Factors Affecting the Aging Reform of the Home Environment in the New Era Background. Urban Hous. 2019, 26, 40-43.

9. Luo, J. Research on the "Adaptable Aging" Transformation of Old Residential Quarters. Mod. Property 2017, 1, 46-47.

10. Li, C. Research on the Renovation of Elderly-Oriented Landscape in Old Residential Area of Shenyang Based on Comfort Optimization. Shenyang Jianzhu Univ. 2019, 26, 8-10.

11. Li, C. Research on the Ageing Reconstruction of Old Multi-Storey Residential Units; Beijing Jiaotong University: Beijing, China, 2018.

12. Zhu, X. Discussion on the needs of the expansion of the activity space of the elderly and the adaptation to the aging-A case study of the old communities in Xiamen. Green Technol. 2018, 21, 70-72.

13. Chen, S.; Zeng, L.; Zeng, C.; Ma, C.; Li, H. Analysis on the needs of affordable housing for aging renovation and renovation design: Taking Nanjing as an example. Hous. Real Estate 2019, 12, 35.

14. Gao, H. Research on Community Pension Planning and Design from the Perspective of Filial Piety Culture; Hunan University: Changsha, China, 2015.

15. Guo, S. Reconstruction of Old Communities to Adapt to Aging under the Guidance of Differentiated Needs: Taking the Qingshan District Community in Wuhan as an Example. In Proceedings of the 60 Years of Planning: Achievements and ChallengesProceedings of 2016 China Urban Planning Annual Conference (17 Housing Construction Planning), Shenyang, China, 24-26 September 2016.

16. Ye, L. Investigation on "Potential Elderly Care Resources" in Rural Areas of Northern Zhejiang; Zhejiang University: Hangzhou, China, 2017.

17. Sanford, J.A.; Butterfield, T. Using remote assessment to provide home modification services to underserved elders. Gerontologist 2005, 45, 389-398. [CrossRef]

18. Andersson, G.; Karlberg, I. Integrated care for the elderly: The background and effects of the reform of Swedish care of the elderly. Int. J. Integr. Care 2000, 1, e01. [CrossRef]

19. Hasson, H.; Arnetz, J.E. Care recipients' and family members' perceptions of quality of older people care: A comparison of home-based care and nursing homes. J. Clin. Nurs. 2011, 20, 9-10. [CrossRef]

20. Luo, X. Aging Design for the Residential Space of the Elderly. Shanghai Arts Crafts 2019, 3, 89-91.

21. Gao, L. Research on the Design of Outdoor Space Suitable for the Elderly in Old Residential Communities. Furnit. Inter. Decor. 2019, 8, 110-111.

22. Zheng, L. A Study on the Ageing Reconstruction of Existing Commercial Residential Districts in Guangzhou; South China University of Technology: Guangzhou, China, 2016.

23. Liang, X.; Shen, G.Q.; Guo, L. Optimizing Incentive Policy of Energy-Efficiency Retrofit in Public Buildings: A Principal-Agent Model. Sustainability 2019, 11, 3442. [CrossRef] 
24. Le, Y.; Zhang, B.; Guan, X.; Li, Y. Research on Collusion of Government Investment Projects Based on SNA Perspective. Public Manag. 2013, 10, 29-40.

25. Liang, X.; Shen, G.Q.; Guo, L. Improving management of green retrofits from a stakeholder perspective: A case study in China. Int. J. Environ. Res. Public Health 2015, 12, 13823-13842. [CrossRef] [PubMed]

26. Liu, Y.; Chen, B. Research on the Strategies for the Adaptability of Urban Existing Communities Based on Demand AnalysisTaking Suzhou City as an Example. Chin. Hosp. Constr. Equip. 2018, 33-36.

27. Dai, X.; Wang, J.; Dong, B. Thoughts on the Reconstruction Mode of Guangzhou Old Community from the Perspective of Community Renewal. Shanghai Urban Manag. 2019, 29, 26-31.

28. Zhang, T. The Value and Renewal Approach to Old Neighborhood and Residential Building Under "Double Aging". Urban Archit. 2018, 21, 20-23.

29. Zhang, J. Research on the Transformation of Urban Communities with Agrochemicals for the Old; Shandong Jianzhu University: Jinan, China, 2017.

30. Xiong, Y. Research on Corporate Participation in Urban Community Governance from the Perspective of Stakeholders; Nanchang University: Nanchang, China, 2019.

31. Wang, J. A Study on the Reconstruction of Urban Residential Districts for the Elderly under the Home-Based Care; Nanchang University: Nanchang, China, 2016.

32. Wang, Y.; Wang, J. “Community Aging” Evaluation and Research on the Strategy of Community Aging Improvement. J. Tianjin Urban Constr. Univ. 2019, 25, 233-238.

33. Chen, Y.; Tian, H. Research on the Countermeasures for the Reconstruction of Old Community under the Background of Community Elderly Care. J. Qingdao Technol. Univ. 2018, 39, 600-645.

34. Qi, J. Research on Multi-Body Cooperative Control under Dynamic Evolutionary Game Mechanism; Wuhan University of Science and Technology: Wuhan, China, 2016.

35. Zhang, Q. The Equilibrium Strategy of Enterprise Technology Innovation Based on Dynamic Evolutionary Game. Sci. Technol. Manag. Res. 2016, 21, 19-33.

36. Guo, D. A Review of the Research on Classification of Stakeholders. J. Fuyang Teach. Coll. (Soc. Sci. Ed.) 2012, 15, 158.

37. Zhao, N. Research on the Benefit Game and Optimization Strategy of Contractual Community Medical Service; Nanchang University: Nanchang, China, 2018.

38. Chen, H.; Jia, S. Empirical analysis on three dimensional classifications of stakeholders in enterprises. Econ. Res. 2003, 4, 80-90.

39. Freeman, R.E. Strategic Management: A Stakeholder Approach; Pitman Publishing: Boston, MA, USA, 1984.

40. Frederick, W.C.; Davis, K.; Post, J.E. Business and Society: Corporate Strategy, Public Policy, Ethics, 6th ed.; McGraw-Hill Companies: New York, NY, USA, 1988.

41. Adey, B.T.; Burkhalter, M.; Martani, C. Defining road service to facilitate road infrastructure asset management. Infrastruct. Asset Manag. 2019, 7, 240-255. [CrossRef]

42. Charkham, J.P. Corporate governance: Lessons from abroad. Eur. Bus. J. 1992, 4, 8.

43. Clarkson, M. A risk based model of stakeholder theory. In Proceedings of the Second Toronto Conference on Stakeholder Theory, Toronto, ON, Canada, May 1994.

44. Clarkson, M.B. A Stakeholder Framework for Analysing and Evaluating Corporate Social Performance; The Academy of Management Review 20; University of Toronto Press: Toronto, ON, Canada, 1995.

45. Mitchell, R.K.; Agle, B.R.; Wood, D.J. Toward a theory of stakeholder identification and salience: Defining the principle of who and what really counts. Acad. Manag. Rev. 1997, 22, 853-886. [CrossRef]

46. Spens, K.M.; Kovács, G. A content analysis of research approaches in logistics research. Int. J. Phys. Distrib. Logist. Manag. 2006, 36, 374-390. [CrossRef]

47. Guercini, S. New qualitative research methodologies in management. Manag. Decis. 2014, 52, 662-674. [CrossRef]

48. Arifin, S.R.M. Ethical considerations in qualitative study. Int. J. Care Sch. 2018, 1, 30-33.

49. Qian, Y.; Ren, H. Research on Stakeholders' Joint Governance of Green Community Projects under the Public-Private Partnership. Urban Dev. Res. 2018, 25, 148-151.

50. Geng, N.; Chen, Q. Analysis on the Behavior of Rural Environmental Management Stakeholders under the Benefit Game-Taking the Pollution Prevention and Control of Rural Livestock and Poultry Farming as an Example. J. Zhengzhou Univ. (Philos. Soc. Sci. Ed.) 2018, 51, 69-73.

51. Jia, S.; Chen, H. Comment on the Definition Method of Stakeholders. J. Foreign Econ. Manag. 2002, 5, $13-18$.

52. Golant, S.M. Affordable clustered housing-care: A category of long-term care options for the elderly poor. J. Hous. Elder. 2008, 22, 3-44. [CrossRef]

53. Sonal, S.; Anupadma, R. Revolutionizing Geriatric Design in Developing Countries: IoT-Enabled Smart Home Design for the Elderly; Wiley: Hobeken, NJ, USA, 2021; p. 193.

54. Soar, J.; Croll, P. Assistive technologies for the frail elderly, chronic illness sufferers and people with disabilities—A case study of the development of a smart home. In Proceedings of the 18th Australasian Conference on Information Systems, Toowoomba, Queensland, Auatralia, 4 December 2007.

55. Behr, R.; Sciegaj, M.; Walters, R.; Bertoty, J.; Dungan, R. Addressing the housing challenges of an aging population: Initiatives by Blueroof Technologies in McKeesport, Pennsylvania. J. Archit. Eng. 2011, 17, 162-169. [CrossRef] 